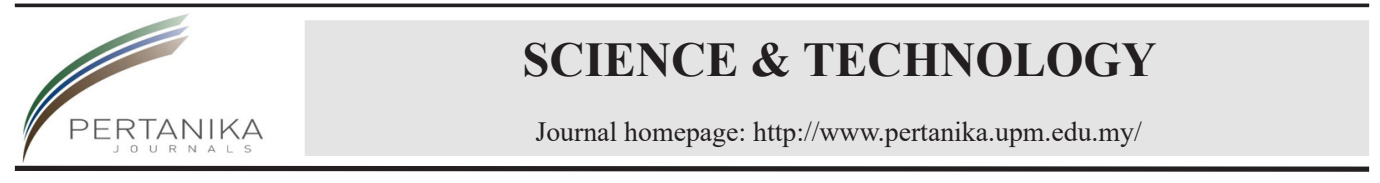

\title{
Development of a Fluidized Bed Dryer for Drying of a Sago Bagasse
}

\author{
Nur Tantiyani Ali Othman* and Ivan Adler Harry \\ Department of Chemical and Process Engineering, Faculty of Engineering and Built Environment, Universiti \\ Kebangsaan Malaysia, 43600, Bangi UKM, Selangor, Malaysia
}

\begin{abstract}
Sago is an essential source of starch for some regions in the third and developing world. However, the sago processing industry has been producing a large amount of sago waste, and the untreated waste is usually disposed to the nearest river. It not only leads to the environmental problem, but it is illegal under the Environmental Quality Act 1974. Since the sago waste still has high starch content, which is $58 \%$, it can be converted to high valueadded products such as poultry feed. However, before being converted to other products, the sago must be dried to remove the moisture content to prevent any bacteria growth and ensure safety health issues have been observed. Recently, drying of sago bagasse using a fluidized bed dryer (FBD) has gained attention since the dry rate of the material is considerably faster compared to other methods. Due to that reason, the drying of the sago bagasse in the FBD is studied using computational fluid dynamic as it can be executed in a short period of time compared to the experimental approach. The FBD model was developed using
\end{abstract}

ARTICLE INFO

Article history:

Received: 17 December 2020

Accepted: 1 April 2021

Published: 19 July 2021

DOI: https://doi.org/10.47836/pjst.29.3.13

E-mail addresses:

tantiyani@ukm.edu.my (Nur Tantiyani Ali Othman)

adlerivan17@gmail.com (Ivan Adler Harry)

*Corresponding author
ANSYS $^{\odot}$ Fluent academic version 19.2. The effect of the hot air feed temperature; $T=50,60,70$, and $80^{\circ} \mathrm{C}$ and velocity of hot air feed; $v=1-4 \mathrm{~m} / \mathrm{s}$ on the sago's behavior and performance of fluidization profile were studied. The simulation results showed that the high temperature and air feed velocity would result in a rapid drying rate. Besides, the optimum drying rate was at $T=60^{\circ} \mathrm{C}$ with the $v=4 \mathrm{~m} / \mathrm{s}$ as these conditions give a shorter drying time to achieve of final $10 \%$ moisture content. It also has the added advantages of reducing the power energy 
and cost supply. These optimal conditions are very crucial and should be consider as the dried sago bagasse tend to be retrograded when a higher temperature is applied.

Keywords: $\mathrm{ANSYS}^{\circ}$ fluent, computational fluid dynamic, drying, fluidized bed dryer, sago bagasse

\section{INTRODUCTION}

Metroxylon sago Rottb, known as sago palm, is a tropical plant capable of adapting to swamps condition and often found in Southeast Asia, especially in a country like Malaysia, Indonesia and Papua New Guinea. It is one of the oldest tropical plant that is exploited by humans for various uses, for instance, as a form of starch providing the primary source of carbohydrate, the leaves and stem are used as pillars or wall, while the sago pith, which is made of fibre can be used as feedstuff, the starch can be used as fuel, and the raw material can be used for cooking (Putra \& Ajiwiguna, 2017). Nowadays, the sago industry is an emergent industry with the potential of sago being the alternative source of starch. In addition, the increase in starch demand further drives this thriving industry, particularly in Malaysia and Indonesia. In Malaysia, Sarawak is the largest producer and exporter with a total of nine active operating processing plants and the export of about 25,000 to 40,000 tonnes of sago products each year (Naim et al., 2016). It has been exported to various countries such as Thailand, Singapore, Japan, and other as well (Bujang, 2008).

Aside from producing the product, this industry also produces a large amount of sago waste or residues which are often mixed with the wastewater and washed off into nearby stream (Vijay et al., 2016). A considerable quantity of the waste effluent has been dumped into the rivers that led to serious environmental problem. Besides, it is a total violation of the environmental Quality Act, 1974. Environmental problem is a worldwide threat to public health; therefore, an alternative method needs to be considered to reduce the discharge of these wastes. Various methods of treatment and conversion of sago has been previously suggested.

The sago effluent has some potential to be converted into alternative high value-added product. As it comprises 58\% starch, 23\% cellulose, 9.2\% hemicellulose, and 4\% lignin, it has potential to be turned into a new product, such as bio-conversion into sugar, as well as converted into animal feedstock (Awg-Adeni et al., 2013). However, before it can be converted to the other products, the sago must be dried to a certain amount of moisture content using a drying process to prevent bacterial growth and maintain product quality. There are currently several drying methods, such as sun direct drying and solar drying. Nevertheless, these methods are less effective due to the unstable rate of drying, and the crops are exposed to an unhealthy environment (Awg-Adeni et al., 2013).

A fluidized bed dryer (FBD) is the most established and regularly used drying method for a solid particle. It is gaining attention as it can produce high heat and mass transfer 
that can ensure a considerably faster and homogeneous drying process. Furthermore, the temperature feed and velocity of hot air can be monitored closely, and the fluidizing action ensures thorough mixing of the substance. In the drying process, the most important is the optimum rate of drying should be achieved in a short time while remaining cost effective. Due to these situations, the computational fluid dynamic (CFD) was conducted to analyze the drying rate and observe the behaviour of the fluidizing rate inside the FBD. In the CFD process, the numerical methods and algorithm were applied in order to solve the problem of fluid flow.

For instance, Arumuganathan et al. (2017) analyzed the drying of mushrooms using an FBD, and they found that the temperature of a hot air feed affects the rate of drying. They also established that the optimum temperature for the drying of mushrooms is $60^{\circ} \mathrm{C}$ (Arumuganathan et al., 2017). Other than that, Mortier et al. (2011) applied the CFD simulation approach to analyze the drying profile of wheat grains in an FBD to predict the moisture content of solids at various drying times by applying Eulerian-Eulerian two-fluid models and the kinetic theory.

Anthony and Shyamkumar (2016) applied the ANSYS ${ }^{\odot}$ Fluent software to observe the drying of sand particles in an FBD (Anthony \& Shyamkumar, 2016). They built a 3D model of FBD and studied innumerable parameters, as well as the velocity and temperature distribution of the inlet hot air. Based on previous studies in the oil palm fronds industry, it was found the higher temperature and velocity of hot air feed cause the drying rate to increase (Puspasari et al., 2014). The higher temperature and velocity also cause the drying rate to increase in the Millet Pearl industry (Maheswari, 2015), and a higher temperature can also result in the increase in the rate of coconut drying (Jongyingcharoen et al., 2019).

Others researcher found that mushrooms' optimum drying rate is at the temperature of $60^{\circ} \mathrm{C}$ (Charles et al., 2012). Besides, the rate of drying decreases as the velocity of hot air feed increases over $5 \mathrm{~m} / \mathrm{s}$ for drying wheat (Li-Zhen et al., 2019). In the case of the coal industry, the drying rate increases as the temperature of hot air feed increases (Dejahang, 2015). When drying grain, and the temperature of hot air at $200^{\circ} \mathrm{C}$ will damage the grain. The optimum drying rate of grains is at a temperature less than $100^{\circ} \mathrm{C}$ (Jannatul et al., 2018). Apart from that, the ideal temperature for sand drying is at $157^{\circ} \mathrm{C}$ (Anthony \& Shyamkumar, 2016).

To gain a deeper understanding of the fluid flow properties in the FBD, aside from the experimental work, the CFD method was proposed. Based on previous numerical studies, the simulation method using CFD has proven in improving design and optimize FBD parameters also able to obtain hydrodynamic data is needed to improve the efficiency of the FBD operation (Hamzehei, 2011; Honarvar \& Mowla, 2012; Jalil \& Nikbakht, 2017; Othman et al., 2020; Rakesh, et al. 2020). Thus, the goal of this study is to determine the relationship between the drying rate of the sago at various hot air velocities and inlet 
temperatures. The profile of the temperature and velocity distribution in the FBD was observed in order to determine the optimum condition for drying of the sago bagasse.

\section{METHODS}

In this study, a CFD simulation was conducted to analyze the drying rate of sago in the FBD. The CFD simulation enabled a fluid flow to be observed, determining the heat and mass transfer and other related phenomena inside the FBD. Using numerical methods and algorithms, CFD was capable of solving and analyzing problems involving fluid mechanics. The standard CFD process consisted of several steps, which included the pre-processing, solver as well the post processing stages.

\section{Pre-Processing - Development of FBD Geometry and Meshing Process}

In this study, the front view, side view and 3D model of the FBD are developed and designed using ANSYS ${ }^{\odot}$ Fluent academic version 19.2 (Ansys, 2019). This FBD model is designed based on previous studied previous studies (Yahya \& Fudholi, 2016; Othman et al., 2020). The dimensions and the design model for FBD are shown as in Figure 1. The model is a cylinder with a diameter of $600 \mathrm{~mm}$ and an overall length of $3000 \mathrm{~mm}$. Two inlets are located at the bottom of the cylinder to supply the hot air inside FBD. Both of the inlets have an inside diameter and length of $60 \mathrm{~mm}$, and the distance between these two inlets is $1000 \mathrm{~mm}$. There is one outlet at the right side with a length of $100 \mathrm{~mm}$, and a diameter of $100 \mathrm{~mm}$ for transportation of the dried sago bagasse.

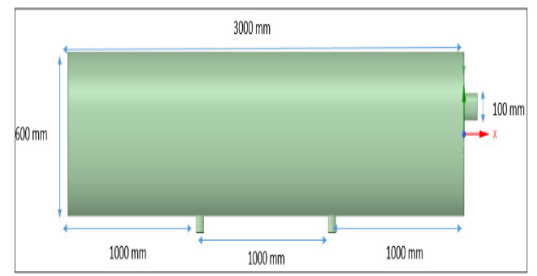

(a)

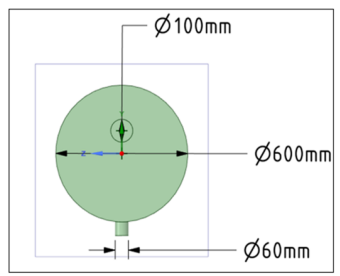

(b)

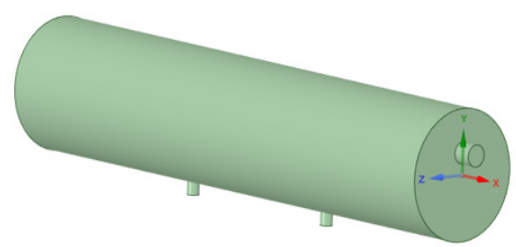

(c)

Figure 1. Front view, side view, and 3D model of the FBD 
The development of meshing was done after the complete model of FBD has been designed. In the meshing process, the size details should be specified where the elements were fine mesh, and a minimum size of $0.0397 \mathrm{~mm}$ was used in this study. Besides, some assumptions were made in this simulation, such as no chemical reaction is taking place during the drying process, well-mixed achieved between the solid and gas phases, no slip condition, the desired final moisture content of the sago is set to be at $10 \%$ (wt./wt.), and the size of the particle is not reduced during the drying process. The $3 \mathrm{D}$ meshing of the FBD model is shown as in Figure 2.

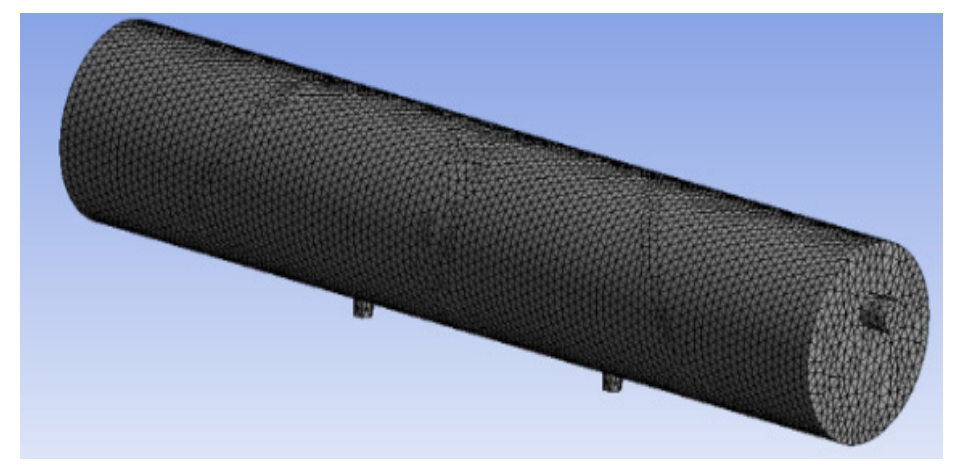

Figure 2.3D Meshing of the FBD model

\section{Define of A Boundary Condition, Materials and Parameters}

Once the problem physics had been identified, the flow physics model and boundary conditions were defined in the ANSYS ${ }^{\odot}$ Fluent 19.2. In this study, the Eulerian-Eulerian multiphase model was applied, and a turbulent model was selected due to the turbulence flow in the FBD. It is because in the turbulent model, the bubble size of sago bagasse particle is not anymore discrete, but continuous and the bubble phase is less distinguishable than in the bubbling regime. From the previous researchers, it shows the bubbling regime simulation is suitable in the pilot plant while, the turbulent model better simulated for industrial scale experiment. As the flow of air increases, the bed known as FBD bag expands, and particles of sago start a turbulent motion. Due to regular contact with air, the sago bagasse gets dry. Besides, to analyze the transfer of heat between the two-phase gas and solid, the heat transfer model was selected as well. The model of the two-term exponential was also chosen in the function to obtain the moisture ratio.

The wet sago bagasse with the high moisture content (MC) was in the feed, and the hot air was supplied through two inlets below the FBD to dry the wet sago. The dried sago bagasse flowed out the FBD through the outlet. The effect of the inlet hot gas velocity on the rate of drying were analyzed at various velocities ranges; $v=1-4 \mathrm{~m} / \mathrm{s}$. In this case, the 
temperature of the hot gas, $T$ and the initial moisture content of sago, $\mathrm{MC}$ was kept constant at $50^{\circ} \mathrm{C}$ and $\mathrm{MC}=80 \%$, respectively. The optimum velocity of the hot air feed and that gives the highest rate of drying was chosen as a parameter condition in the next simulation in order to determine the effect of temperature on the rate of drying. Then, the effect of the temperature of hot gas; $T=50-80^{\circ} \mathrm{C}$ was studied to observe the optimum and the highest rate of drying of the sago bagasse where the air feed velocity and initial moisture content was kept constant at $v=4 \mathrm{~m} / \mathrm{s}$ and $\mathrm{MC}=80 \%$, respectively.

\section{Define of A Boundary Condition, Materials and Parameters}

The governing equation used in this study is a conservation of mass and momentum. The conservation of energy and turbulence model is also important to indicate heat transfer and turbulence flow (Argyropoulos \& Markatos, 2015). Equation 1 to 7 were applied to the physics model of the simulation to solve the problem involving fluid flow and fluid mechanics in the FBD where $\overrightarrow{v_{q}}$ is a velocity for $q$ phase, $p$ is pressure, $\dot{m}_{p q}$ is a mass transfer from $p$ phase to $q$ phase, $\dot{m}_{q p}$ is a mass transfer from $q$ phase to $p$ phase, $h$ is a heat transfer coefficient, $\rho$ is a density, $q$ is a heat flux, $\varepsilon$ is a volume fraction, $Q$ is a heat transfer rate, $v$ is a vector velocity, $H$ is a latent heat and $\tau$ is a shear stress tensor. In the ANSYS ${ }^{\odot}$ Fluent simulation, the modules used are electrical current, creeping flow, particle tracing in a fluid flow and transport of species. The electric current module was used to supply the non-uniform electric current fields. The creeping flow was used to simulate fluid flow at very low Reynolds numbers where the inertia term in the Navier-Stokes equation can be ignored.

Conservation of mass (Equation 1),

$$
\frac{\delta}{\delta t}\left(\alpha_{q} \rho_{g}\right)+\nabla \cdot\left(\alpha_{q} \rho_{q} \overrightarrow{v_{q}}\right)=\sum_{p=0}^{n}\left(\dot{m}_{p q}-\dot{m}_{q p}\right)+S_{q}
$$

Conservation of momentum (Equation 2),

$$
\frac{\delta}{\delta t}\left(\varepsilon_{s} \rho_{s}\right)+\nabla \cdot\left(\varepsilon_{s} \rho_{s} v_{s}\right)=0
$$

i) For gas phase (Equation 3),

$$
\begin{aligned}
& \frac{\delta}{\delta t}\left(\varepsilon_{g} \rho_{g} v_{g}\right)+\nabla \cdot\left(\varepsilon_{g} \rho_{g} v_{g} v_{g}\right) \\
& =-\varepsilon_{g} \nabla p+\nabla \tau_{g}^{=}+\varepsilon_{g} \rho_{g} g+K_{g s}\left(\overrightarrow{v_{g}}-\overrightarrow{v_{s}}\right)
\end{aligned}
$$


ii) For solid phase (Equation 4),

$$
\begin{aligned}
& \frac{\delta}{\delta t}\left(\varepsilon_{s} \rho_{s} v_{s}\right)+\nabla \cdot\left(\varepsilon_{s} \rho_{s} v_{s} v_{s}\right) \\
& =-\varepsilon_{s} \nabla p+\nabla p_{s}+\nabla \tau_{s}^{=}+\varepsilon_{s} \rho_{s} g+K_{s g}\left(\overrightarrow{v_{g}}-\overrightarrow{v_{s}}\right)
\end{aligned}
$$

Continuity equation for solid phase (Equation 5),

$$
\frac{\delta}{\delta t}\left(\varepsilon_{s} \rho_{s}\right)+\nabla \cdot\left(\varepsilon_{s} \rho_{s} v_{s}\right)=0
$$

Conservation of Energy

i) For gas phase (Equation 6),

$$
\begin{aligned}
& \frac{\delta}{\delta t}\left(\varepsilon_{g} \rho_{g} h_{g}\right)+\nabla \cdot\left(\varepsilon_{g} \rho_{g} v_{g} h_{g}\right) \\
& =-\varepsilon_{g} \frac{\delta p_{g}}{\delta t}+\tau_{g}^{=}: \nabla \vec{v}_{g}-\nabla \vec{q}_{g}+Q_{s g}+\dot{m} \Delta H_{v a p}
\end{aligned}
$$

ii) For solid phase (Equation 7),

$$
\begin{aligned}
& \frac{\delta}{\delta t}\left(\varepsilon_{s} \rho_{s} h_{s}\right)+\nabla \cdot\left(\varepsilon_{s} \rho_{s} u_{s} h_{g}\right) \\
& =-\varepsilon_{s} \frac{\delta p_{s}}{\delta t}+\tau_{s}^{=}: \nabla \vec{u}_{s}-\nabla \vec{q}_{s}+Q_{g s}-\dot{m} \Delta H_{v a p}
\end{aligned}
$$

\section{RESULTS AND DISCUSSIONS}

To inhibit any microbial development and quality decay in the dried sago bagasse as well for storage handling, achieving an ideal drying parameter condition during the early stages is crucial in the drying process. In this simulation study, a final sago volume fraction and a mass fraction of water in the sago bagasse in the FBD were observed and determined at different ranges of inlet hot air velocities and temperatures. The effect of various hot air velocity; $1.0-4.0 \mathrm{~m} / \mathrm{s}$ on the rate of sago's drying is observed, as shown in Figure 3 where the volume fraction of the sago in the FBD is determined after 5 minutes of the drying process with the feed of the hot gas is supplied at the constant temperature of $\mathrm{T}=70^{\circ} \mathrm{C}$ and the initial moisture content of $\mathrm{MC}=80 \%$. The contour of the color bar indicates the range value of the volume fraction of the sago bagasse in the FBD, with the red color showing a higher sago volume fraction. The value of 1.0 indicates almost all the areas in the FBD are covered by sago bagasse. In contrast, the blue color shows a low sago volume fraction in the FBD as a value of zero indicates no sago bagasse can be found in the area.

The right side of Figure 3 shows the cross-sectional view of the inside FBD near the outlet area, while the left side of Figure 3 shows the front view along the FBD. It is shown that the velocity inside the FBD is uneven in all areas where at the higher inlet hot air velocity of $v=3$ and $4 \mathrm{~m} / \mathrm{s}$, the sago bagasse is fluidized more vigorously on the upper 


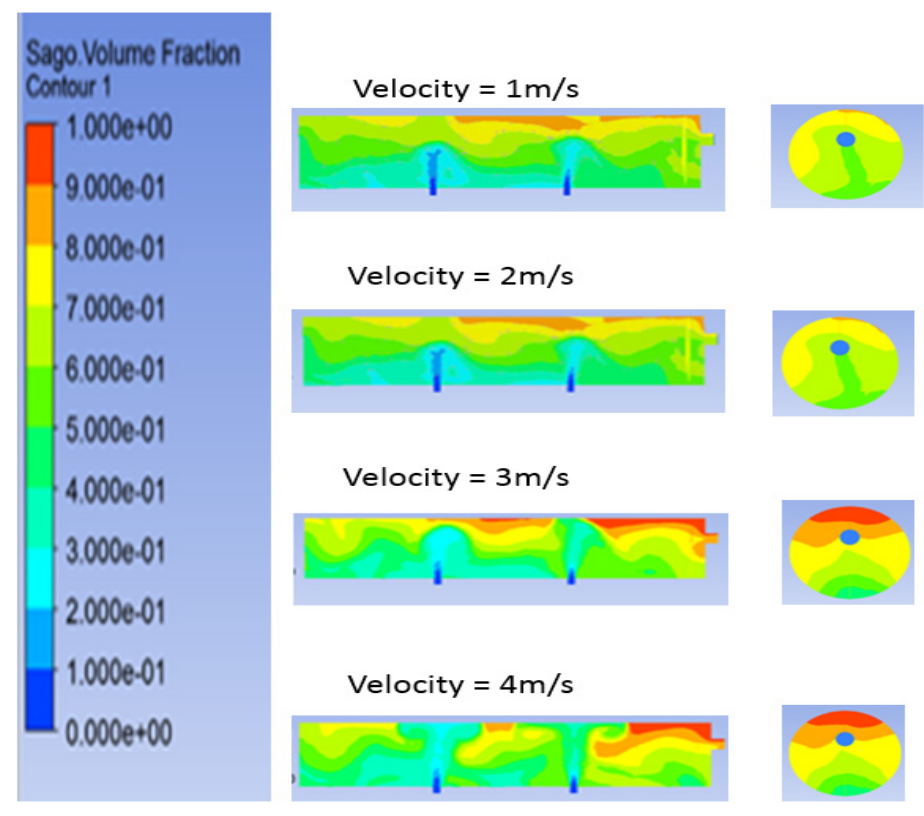

Figure 3. Sago volume fraction distribution in the FBD at various hot air velocities

side of the FBD area. It shows the higher sago fraction with the red color due to higher velocity supplied by hot air from below the FBD, as compared to the lower velocity at $v=1$ and $2 \mathrm{~m} / \mathrm{s}$. The cross-sectional view shows that at $v=1$ and $2 \mathrm{~m} / \mathrm{s}$, the sago is almost evenly spread inside the FBD. The yellowish-green color is observed, which indicates that most area of the FBD are covered with around 50-70\% of the sago content. It shows the moisture content of the sago bagasse is reduced from $80 \%(\mathrm{v} / \mathrm{v})$ up to $50 \%(\mathrm{v} / \mathrm{v})$ after going through the drying process when the velocity at $v=1$ and $2 \mathrm{~m} / \mathrm{s}$ was used.

Meanwhile, with the increment of the hot air velocity at $v=3$ and $4 \mathrm{~m} / \mathrm{s}$, the higher fraction of the sago bagasse causes around $90-100 \%$ of the sago content to be at the top area of the FBD near the outlet area. This happens due to the fluidization process which occurs inside the FBD because the hot air supply increases the particle's movement and reduce the moisture content of the sago bagasse. It can be concluded that the higher velocity will increase the drying rate due to the rapid movement of air.

Based on these simulation results, the percentage of a water loss of the dried sago bagasse can be calculated using Equation 8 , where $W_{\text {final }}$ is the final moisture content of the sago and $W_{\text {initial }}$ is the initial moisture content of water. Figure 4 shows the result of the percentage of the final moisture content against drying time at various air velocities. It shows the drying time needs to achieve the desired and the standard requirement of the final moisture of the sago bagasse is at $\mathrm{MC}=10 \%$ which is the fastest condition, which only 
takes about 11 minutes when the velocity of hot air is at $v=4 \mathrm{~m} / \mathrm{s}$. While, at $v=1 \mathrm{~m} / \mathrm{s}$, the time needed is considerably longer, which is around 16 minutes. This shows that the higher velocity does not have significant effect; the velocity at $v=3-4 \mathrm{~m} / \mathrm{s}$ indicates the optimum condition has been achieved where all the sago bagasse has already had been fluidized.

$$
\% \text { Water loss }=\frac{W_{\text {Final }}-W_{\text {initial }}}{W_{\text {initial }}} \times 100
$$

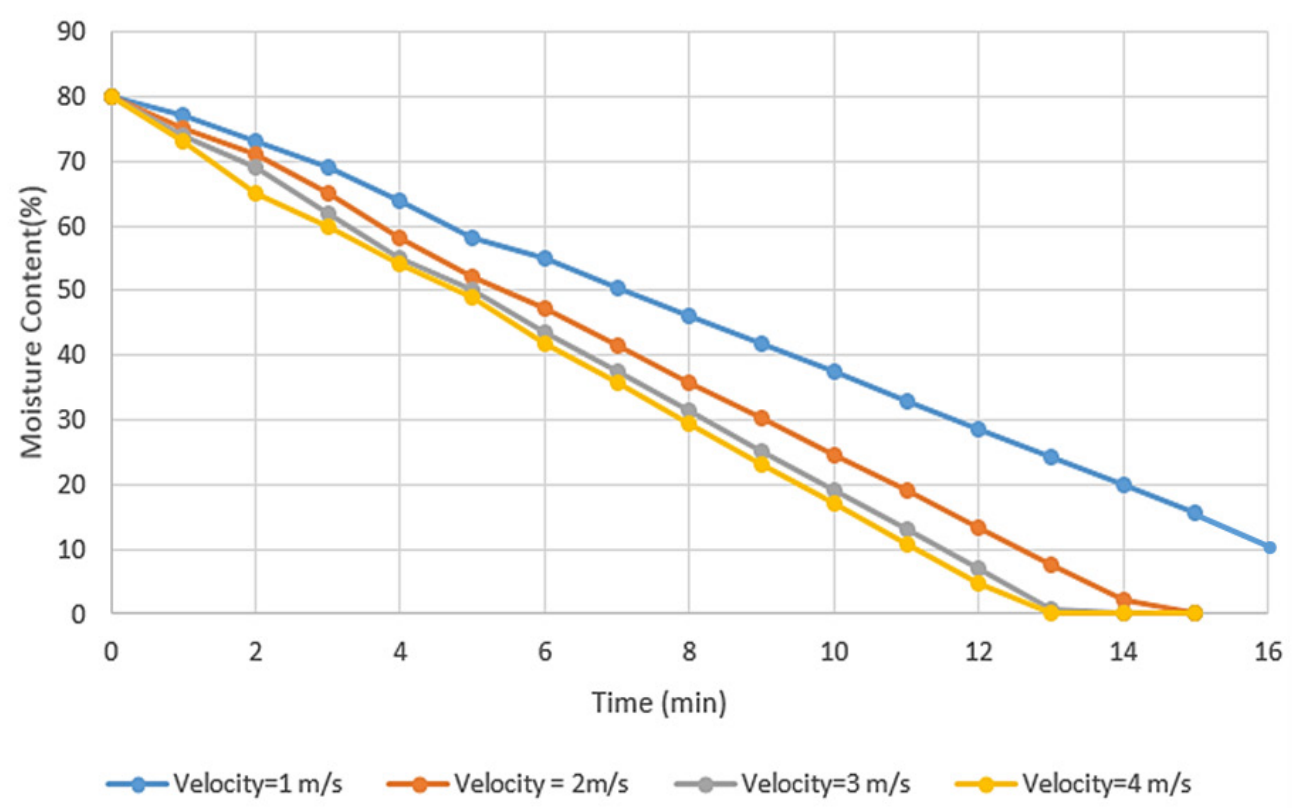

Figure 4. Moisture content of sago bagasse at different inlet velocities of hot gas

Figure 5 shows the flow profile of the sago volume fraction inside the FBD in 35s-time simulation. The colour bar represents the sago volume fraction, where the red color shows the area that has been occupied with the sago bagasse, while the blue color represents the area that has been occupied with the hot air. At $t=0 \mathrm{~s}$, it shows the almost of the lower part areas in the FBD are covered by sago bagasse, as shown by the red colour. As the drying times take placed, the volume fractions of the sago bagasse have slightly decreased, which is represented by the decrease in the level of red color distribution inside the FBD. It occurs because the sago bagasse was fluidized inside the FBD with the existence of hot air supplies that increase the particle movement and reduce the moisture content of the sago bagasse. It shows the cooling effect that occurs in the FBD as a result of the endothermic reaction from the evaporation process of the water from the sago particle's surface. 


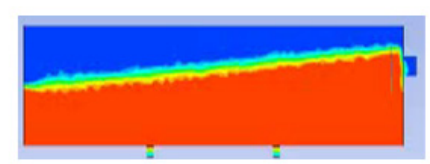

(a) At $t=0 \mathrm{~s}$

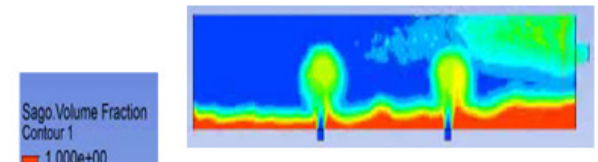

(c) At $t=5 \mathrm{~s}$

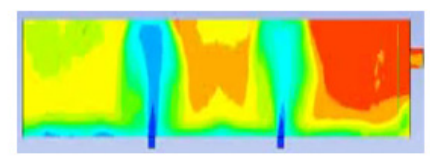

(e) At $t=15 \mathrm{~s}$

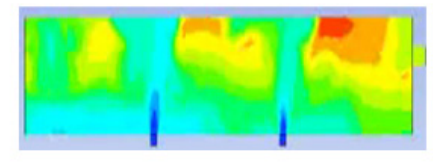

(g) At $t=25 \mathrm{~s}$

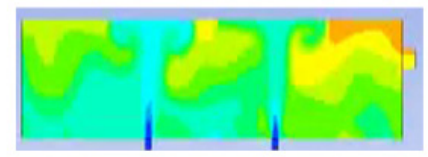

(i) At $t=35 \mathrm{~s}$

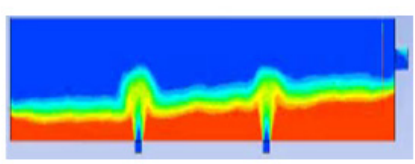

(b) At $t=1 \mathrm{~s}$

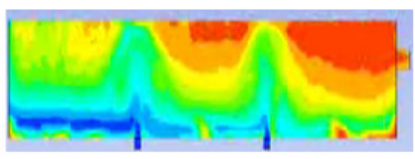

(d) At $t=10 \mathrm{~s}$

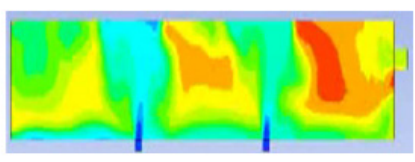

(f) At $t=20 \mathrm{~s}$

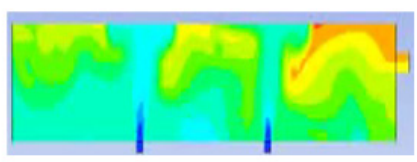

(h) At $t=30 \mathrm{~s}$

Figure 5. Flow profile of the sago volume fraction inside the FBD at various times

Apart from that, the effect of the temperature on the rate of drying was also studied. Figure 6 shows the temperature profile inside the FBD after the sago bagasse has dried in the $35 \mathrm{~s}$ time simulation as the hot air is supplied at the bottom side of the FBD. The color bar represents the temperature distribution where the red color shows the highest temperature in the FBD with the value of $T=70^{\circ} \mathrm{C}$. Meanwhile the blue color represents the lowest temperature profile with the value $T=25^{\circ} \mathrm{C}$. At $t=0 \mathrm{~s}$, it shows the temperature in the FBD is read as room temperature, which is shown by the blue color. As time elapsed, the temperature in the FBD increases from the point of the hot air feed, which helps the drying process of the sago bagasse. It occurs as the heat transfer takes a place inside the FBD due to evaporation process that occurs on the sago particle's surface. This evaporation process is an endothermic reaction where it cools down the surrounding air inside the FBD. This observation of the temperature flow pattern is in agreement with the experimental work done by Okoronkwo et al. (2013) and simulation work done by Othman et al. (2020). As the time elapsed, the temperature distribution inside the FBD was constant, implying that the drying process has occurred by reducing the water content in the sago bagasse. It also 


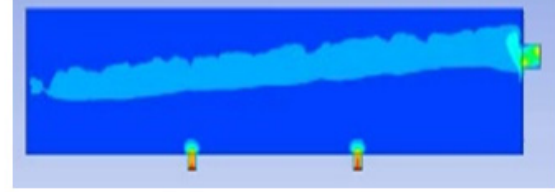

(a) At $t=0 \mathrm{~s}$

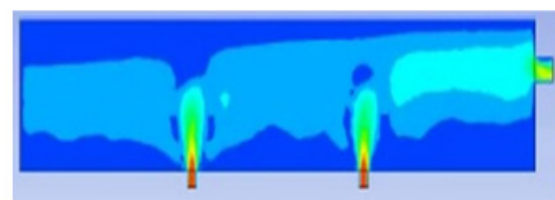

(c) At $t=5 \mathrm{~s}$

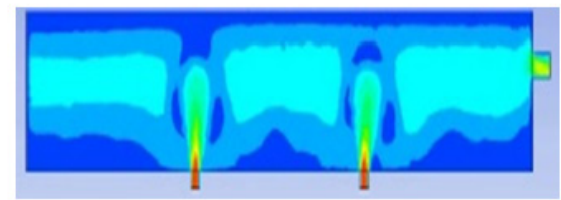

(e) At $t=20 \mathrm{~s}$

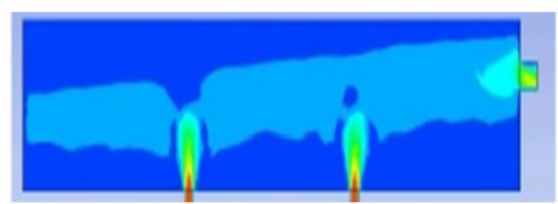

(b) At $t=1 \mathrm{~s}$

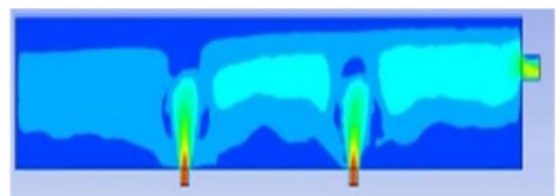

(d) At $t=10 \mathrm{~s}$

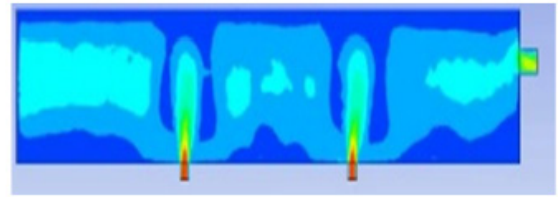

(f) At $t=35 \mathrm{~s}$

Figure 6. Profile of temperature distribution inside the FBD at various drying times

shows the inlet air feed with those velocities' ranges is sufficient to initiate the fluidization of the sago bagasse process in the designed FBD.

Figure 7 shows the effect of the inlet temperature on the sago volume fraction in the FBD after 5 minutes of a drying process with the hot air was feed at a constant velocity of $v=4 \mathrm{~m} / \mathrm{s}$ and the initial moisture content of $\mathrm{MC}=80 \%$. The right side of Figure 7 shows the cross-sectional view of FBD near the outlet area where the dried sago bagasse distribution does not show any significant difference due to the similar velocity used. However, as the temperature of $T=50^{\circ} \mathrm{C}$ is applied, it can be seen that a higher fraction of sago is observed at the top area of the FBD, indicated by the red color compared to the other tested temperatures.

Based on these simulation results, the drying time needed to achieve the desired of the final moisture content at various inlet hot air temperatures are demonstrated in Figure 8. Figure 8 shows the time taken for the initial moisture content of the sago bagasse to reduce to $\mathrm{MC}=10 \%$ is the shortest time which is less than 9 minutes with $T=80^{\circ} \mathrm{C}$. Meanwhile, the time needed to achieve the $\mathrm{MC}=10 \%$ when the hot air feed is at $T=50^{\circ} \mathrm{C}$ is around 11 minutes. Thus, it can be concluded that the higher hot air temperature will increase the rate of drying. In this study, the optimum condition of hot air supplied at $v=4 \mathrm{~m} / \mathrm{s}$ is selected because, under this condition, a shorter drying time can be achieved to obtain the final $10 \%$ moisture content compared to others, and a further increase of the inlet velocity will affect 


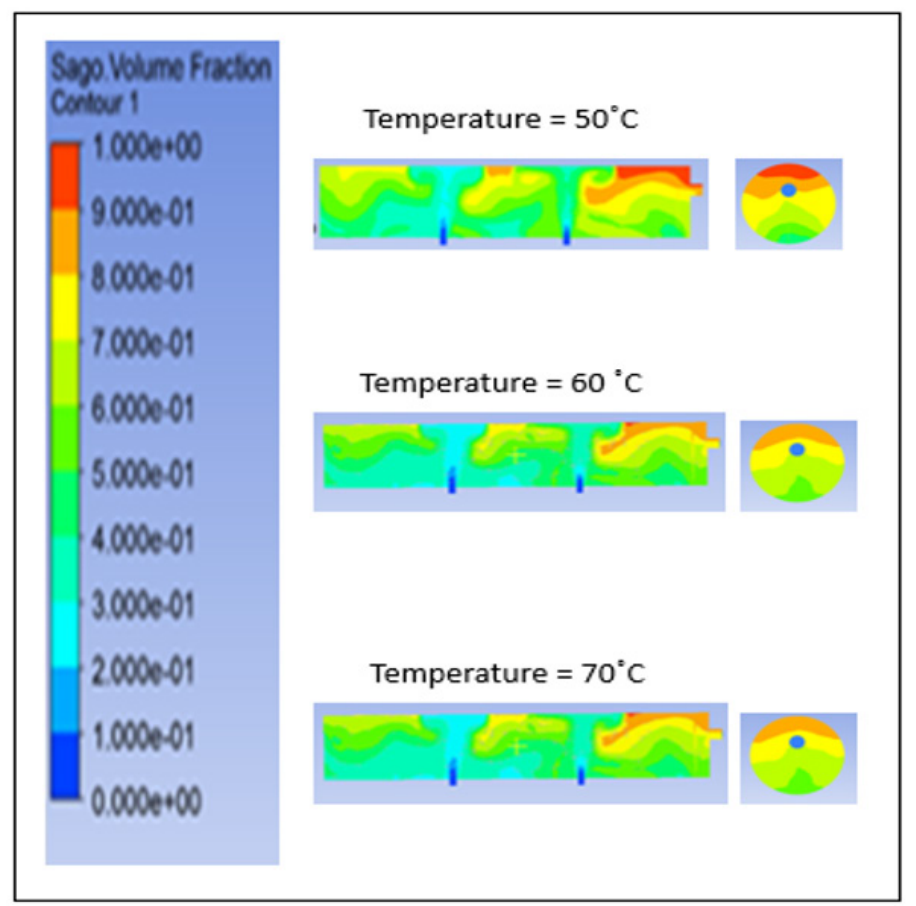

Figure 7. Sago volume fraction inside the FBD at various temperature with similar hot air velocity and moisture content

the power energy and increase the cost. For the hot air feed temperature, $T=60^{\circ} \mathrm{C}$ is selected as the optimum condition shows that $T=50-70^{\circ} \mathrm{C}$, as listed in Figure 8, is ideal for drying sago bagasse compared to others. It has a similar pattern to $T=80^{\circ} \mathrm{C}$ used in previous studies, but the sago bagasse tends to be gelatinous at a higher temperature. Thus, the optimum temperature of $T=60{ }^{\circ} \mathrm{C}$ and velocity of $v=4 \mathrm{~m} / \mathrm{s}$ is selected based on the highest drying rate of sago bagasse. At this velocity, it will support the sago particle to fluidize as well to reduce the moisture content in the final sago bagasse. Thus, higher inlet temperatures of drying air should be met, which leads to shorter drying times. However, the product quality considerations limit the applicable rise to the air temperature (Mujumdar, 1995; Daud, 2008). Excessive hot air can almost completely dehydrate the sago bagasse surface, making its pores shrink and almost close, leading to crust formation or "case hardening", which is usually undesirable. 


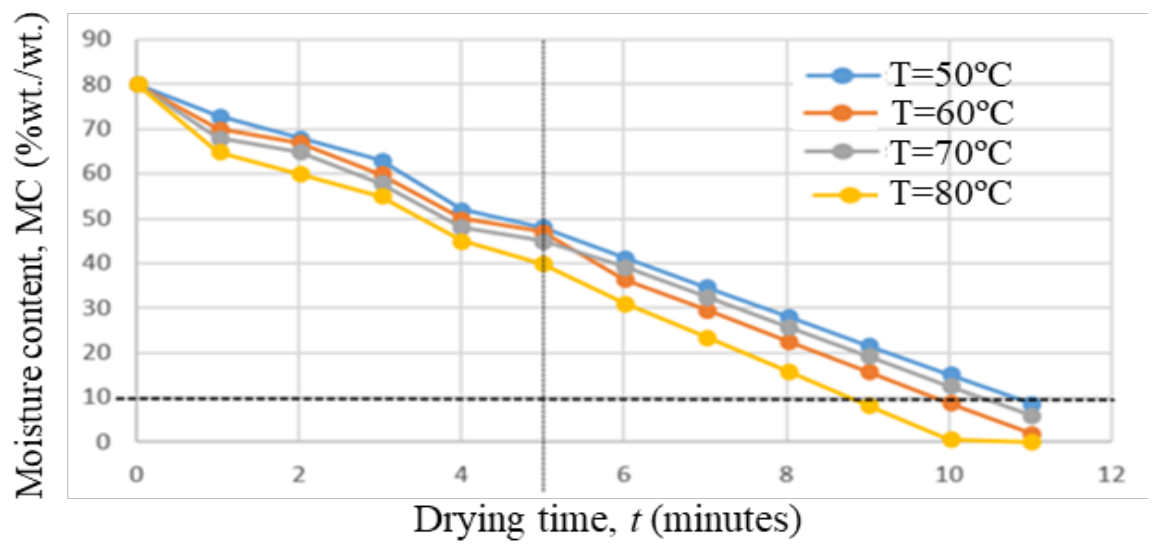

Figure 8. Moisture content against time with different temperature of hot air feed

\section{CONCLUSION}

The 3D FBD model was successfully designed by using ANSYS $^{\odot}$ Fluent academic version 19.2. The simulations were done to study the effect of various ranges of the temperature and velocity of the inlet hot air on the rate of drying of sago bagasse. The simulation results show that the higher inlet velocity, as well as the higher temperature feed, will result in a faster rate of drying. The temperature of $T=60{ }^{\circ} \mathrm{C}$ and velocity of $v=4 \mathrm{~m} / \mathrm{s}$ are selected as the value optimum condition for the drying of sago. This result indicates sago bagasse's feasibility to be converted for animal feed and other high-value products. For future improvements, the study will be expanding to a wide range of operational parameter for more reliable data.

\section{ACKNOWLEDGEMENT}

The authors would like to thank Universiti Kebangsaan Malaysia for their financial support under the grants GUP-2017-063 and FRGS/1/2020/TKO/UKM03/2.

\section{REFERENCES}

Ansys, Inc. (2019). Ansys fluent in Ansys workbench user's guide. Ansys, Inc.

Anthony, J., \& Shyamkumar, B. (2016). Study on sand particles drying in a fluidized bed dryer using CFD. International Journal of Engineering Studies, 8(2), 129-145.

Argyropoulos, C. D., \& Markatos, N. C. (2015). Recent advances on the numerical modelling of turbulent flows. Applied Mathematical Modelling, 39(2), 693-732. https://doi.org/10.106/j.apm.2014.07.001

Arumuganathan, T., Manikantan, M. R., Ramanathan, M., Rai, R. D., Indurani, C., \& Karthiayani, A. (2017). Effect of diffusion channel storage on some physical properties of button mushroom (Agaricus bisporus) and shelf-life extension. Proceedings of the National Academy of Sciences, India Section B: Biological Sciences, 87(3), 705-718. https://doi.org/10.1007/s40011-015-0628-4 
Awg-Adeni, S., Abd-Aziz, S., Bujang, K., \& Hassan, A. (2013). Recovery of glucose from residual starch of sago hampas for bioethanol production. BioMed Research Corporation, 9(14), 1-8. https://doi. org/10.1155/2013/935852

Bujang, B. (2008). Potentials of bioenergy from the sago industries in Malaysia. In H. W. Doelle, S. Rokem \& M. Berovic (Eds.), Encyclopedia of Life Support System (pp. 124-136). Eolss Publishers Co. Ltd.

Charles, M., David, K., \& Brenda, N. (2012). Effect of pretreatments and drying methods on chemical composition and sensory evaluation of oyster mushroom (Pluerotus oestreatus) powder and soup. Journal of Food Processing and Preservation, 38(1), 457-465. https://doi.org/10.1111/j.1745-4549.2012.00794.x

Daud, R. W. (2008). Fluidized bed dryers-recent advances. Advanced Powder Technology, 19, 403-418. https:// doi.org/10.1163/156855208x336675

Dejahang, T. (2015). Low temperature fluidized bed coal drying experiment, analysis and simulation (Master Thesis). University of Alberta, Canada.

Hamzehei, M. (2011). CFD modeling and simulation of hydrodynamics in fluidizedbed dryer with experimental validation. ISRN Mechanical Engineering, 2011, 1-9. https://doi.org/10.5402/2011/131087

Honarvar, B., \& Mowla, D. (2012). Theoretical and experimental drying of a cylindrical sample by applying hot air and infrared radiation in an inert medium fluidized bed. Brazilian Journal of Chemical Engineering, 29(2), 231-242. https://doi.org/10.1590/s0104-66322012000200004

Jalil, N., \& Nikbakht, A. M. (2017). Numerical simulation of corn drying in a hybrid fluidized bed-infrared dryer. Journal of Food Process Engineering, 40(2), Article e12373. https://doi.org/10.1111/jfpe.12373

Jannatul, A., Qinfu, H., \& Aibing, Y. (2018). Discrete particle simulation of food grain drying in a fluidised bed. Powder Technology, 323, 238-249. https://doi.org/10.1016/j.powtec.2017.10.019

Jongyingcharoen, J. S., Wuttigarn, P., \& Assawarachan, R. (2019). Hot air drying of coconut residue: Shelf life, drying characteristics, and product quality. IOP Conference Series: Earth and Environmental Science, 301, Article 012033. https://doi.org/10.1088/1755-1315/301/1/012033

Li-Zhen, D., Arun, S. M., Qian, Z., Xu-Hai, Y., Jun, W., Zhi-An, Z., Zhen-Jiang, G., \& Hong-Wei, X. (2019). Chemical and physical pretreatments of fruits and vegetables: Effects on drying characteristics and quality attributes - A comprehensive review. Critical Reviews in Food Science and Nutrition, 59(9), 1408-1432. https://doi.org/10.1080/10408398.2017.1409192

Maheswari, S. (2015). Drying of pearl millet using fluidised bed dryer: Experiments and modelling. International Journal of ChemTech Research, 8(1), 377-387.

Mortier, C., De Beer, T., Remon, J. P., VerVaet, C., \& Nopens, I. (2011). Mechanistic modelling of fluidized bed drying processes of wet porous granules: a review. European Journal of Pharmaceutics and Biopharmaceutics, 79(2), 205-225. https://doi.org/10.1016/j.ejpb.2011.05.013

Mujumdar, A. (1995). Handbook of industrial drying (2nd Ed.). Dekker Publishing.

Naim, M., Yaakub, A. N. H., \& Awang, H. D. A. (2016). Commercialization of sago through estate plantation scheme in Sarawak: The way forward. International Journal of Agronomy, 2016, Article 8319542. https:// doi.org/10.1155/2016/8319542. 
Orokonkwo, C. A., Nwufo, O. C., Nwaigwe, K. N., Oguuke, N. V., \& Anyanmwu, E. (2013). Experimental evaluation of a fluidized bed dryer performance. The International Journal of Engineering and Science, $2(6), 45-53$.

Othman, N. T. A. , Din, Z. A. M., \& Taakrif, S. M. (2020). Simulation on drying of sago bagasse in a fluidized bed dryer. Journal of Engineering Science and Technology, 15(4), 2507-2521.

Puspasari, I., Meor, Z., Daud, D. W., \& Tasirin, S. (2014). Characteristic drying curve of oil palm fibers. International Journal on Advanced Science, Engineering and Information Technology, 4(1), 20-24. https:// doi.org/10.18517/ijaseit.4.1.361

Putra, N., \& Ajiwiguna, A. (2017). Influence of air temperature and velocity for drying process. Procedia Engineering, 170, 516-519. https://doi.org/10.1016/j.proeng.2017.03.082

Rakesh, V., \& Paliwal, H. K. (2020). Simulation and analysis of plug flow fluidized bed dryer. nternational Journal of Innovative Technology and Exploring Engineering, 9(7), 805-811. https://doi.org/10.35940/ ijitee.g5338.059720

Vijay, K. G., Uttara, S., \& Amrita, B. (2016). Bioconversion technologies of crude glycerol to value added industrial products. Biotechnology Reports, 9, 9-14. https://doi.org/10.1016/j.btre.2015.11.002

Yahya, M., \& Fudholi, A. (2016). Performances of fluidized bed drying integrated with biomass furnace for drying of paddy. Research Journal of Applied Sciences, Engineering and Technology, 13(6), 473-480. https://doi.org/10.19026/rjaset.13.3007 
